\title{
Erratum to: Cytoplasm-predominant Pten associates with increased region-specific brain tyrosine hydroxylase and dopamine D2 receptors in mouse model with autistic traits
}

Xin He ${ }^{1,2}$, Stetson Thacker ${ }^{1,2,3}$, Todd Romigh ${ }^{1,2}$, Qi Yu ${ }^{1,2}$, Thomas W. Frazier Jr $r^{1,2,3,4,5}$ and Charis Eng ${ }^{1,2,3,6,7,8,9^{*}}$

\section{Erratum}

We have just noticed a minor error in Fig. 1a of our article [1]. The $\mathrm{m} 3 \mathrm{~m} 4$ mutation was described incorrectly as it improperly describes two Pten mutations, R233N and K269N. However, the confirmed sequence data on the $\mathrm{m} 3 \mathrm{~m} 4$ mutation indicates there are five nucleotide changes, as we have previously published [2], resulting in four amino acid changes: R233Q, R234Q, K265N, and K266Q. The fifth nucleotide change is a synonymous mutation, L264L. For greater clarity on the details of the nucleotide changes and the corresponding amino acid changes of the $\mathrm{m} 3 \mathrm{~m} 4$ mutation, they have been provided:

\begin{tabular}{ccccccccccc}
\multicolumn{1}{c}{ NLS3 } & \multicolumn{1}{c}{ NLS4 } \\
Amino Acid & 233 & 234 & 235 & 236 & 237 & 264 & 265 & 266 & 267 & 268 \\
PTEN-WT & CGA-CGG-GAA-GAC-AAG--------CTT-AAA-AAG-GAC-AAA \\
& R & R & E & D & K & L & K & K & D & K \\
PTEN-m3m4 & CAA-CAG-GAA-GAC-AAG-------CTC-AAC-CAG-GAC-AAA \\
& Q & Q & E & D & K & L & N & Q & D & K
\end{tabular}

Additionally, the included Fig. 1a now shows the correct amino acid changes. We apologize for any confusion caused by this error.

\footnotetext{
*Correspondence: engc@ccf.org

1 Genomic Medicine Institute, Cleveland Clinic, 9500 Euclid Avenue, Mailstop NE-50, Cleveland OH 44195, USA

${ }^{2}$ Lerner Research Institute, Cleveland Clinic, Cleveland, OH, USA

Full list of author information is available at the end of the article
} 
1

Phosphatase domain $-\underbrace{\mathrm{C} 2 \text { domain }}_{\overline{\mathrm{M} 3} \overline{\mathrm{M}} 4}$

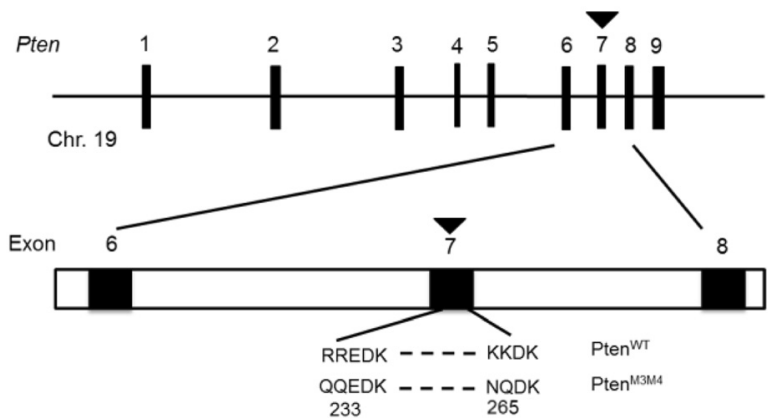

Fig. 1 a. NLS-like region of Pten and the missense mutations created in the NLS-like region

\section{Author details}

${ }^{1}$ Genomic Medicine Institute, Cleveland Clinic, 9500 Euclid Avenue, Mailstop NE-50, Cleveland OH 44195, USA. 'Lerner Research Institute, Cleveland Clinic, Cleveland, OH, USA. ${ }^{3} \mathrm{HHMI}$ Graduate Program, Department of Molecular Medicine, Cleveland Clinic Lerner College of Medicine, Cleveland Clinic Lerner College of Medicine, Case Western Reserve University School of Medicine, Cleveland, OH, USA. ${ }^{4}$ Center for Autism, Pediatrics Institute, Cleveland Clinic, Cleveland, OH, USA. ${ }^{5}$ Department of Pediatrics, Case Western Reserve University School of Medicine, Cleveland, OH, USA. ${ }^{6}$ Taussig Cancer Institute, Cleveland Clinic, Cleveland, OH, USA. ${ }^{7}$ Stanley Shalom Zielony Institute of Nursing Excellence, Cleveland Clinic, Cleveland, OH, USA.

${ }^{8}$ Department of Genetics and Genome Sciences, Case Western Reserve University School of Medicine, Cleveland, OH, USA. ${ }^{9}$ CASE Comprehensive Cancer Center, Case Western Reserve University School of Medicine, Cleveland, $\mathrm{OH}$, USA.

Published: 3 February 2016

\section{Reference}

1. He X, Thacker S, Romigh T, Yu Q, Frazier Jr TW, Eng C. Cytoplasm-predominant Pten associates with increased region-specific brain tyrosine hydroxylase and dopamine D2 receptors in mouse model with autistic traits. Mol Autism. 2015;6:63.

2. Tilot AK, Gaugler MK, Yu Q, Romigh T, Yu W, Miller RH, et al.

Germline disruption of Pten localization causes enhanced sex-dependent social motivation and increased glial production. Hum Mol Genet. 2014; 23(12): 3212-27. doi:10.1093/hmg/ddu031.

\section{Submit your next manuscript to BioMed Central and take full advantage of:}

- Convenient online submission

- Thorough peer review

- No space constraints or color figure charges

- Immediate publication on acceptance

- Inclusion in PubMed, CAS, Scopus and Google Scholar

- Research which is freely available for redistribution

Submit your manuscript at www.biomedcentral.com/submit 